\title{
Responses of Semi-Rigid Base Asphalt Pavement with Interlayer Contact Bonding Model
}

\author{
Xuntao Wang (iD) and Xuanlong Ma \\ School of Science, Xi'an Shiyou University, Xi'an, China \\ Correspondence should be addressed to Xuntao Wang; wxt5288@126.com
}

Received 30 May 2020; Revised 27 July 2020; Accepted 30 July 2020; Published 17 August 2020

Academic Editor: Daniele Baraldi

Copyright (c) 2020 Xuntao Wang and Xuanlong Ma. This is an open access article distributed under the Creative Commons Attribution License, which permits unrestricted use, distribution, and reproduction in any medium, provided the original work is properly cited.

In this paper, an interlayer contact bonding model according to the Coulomb friction model was developed by contact element and target element to accurately simulate the bonding condition between the adjacent layers of semi-rigid base asphalt pavement. The interlayer contact bonding model can be used to not only simulate the partial bond condition between adjacent layers but also imitate the phenomenon of bonding failure between adjacent layers. Semi-rigid base asphalt pavement structure, finite element mesh, material property with temperature, kinds of interlayer bonding failure, and moving load were explained in detail, and the responses of the semi-rigid base asphalt pavement structure were calculated and analyzed by this model at the room temperature and the higher temperature. The results indicated that the disengaging area between the asphalt concrete layer and the base layer can negatively affect the strain responses of asphalt pavement, especially at the higher temperature, and it can also weaken the asphalt pavement performance with the increase of the disengaging area. The deformation of semi-rigid base asphalt pavement is intensified under the action of the high temperature and the overloads, which would be easy to result in potential pavement structural deficiency. At the higher temperature, the adverse effect of moving loads on asphalt pavement is greater than that of roadbed, and the responses of the asphalt pavement decrease with the increase of the vehicle speed.

\section{Introduction}

Semi-rigid base asphalt pavement is generally constituted by asphalt concrete, semi-rigid base, subbase, and subgrade layer, which is typically multilayered composite structure. Semi-rigid base asphalt pavement can effectively transfer and distribute the external loading to the subgrade layers, so it is widely used in pavement structure design. The response model of semi-rigid base asphalt pavement is by far one of the most important components of pavement design and performance prediction, and the bonding condition between adjacent layers has a significant effect on the structural response and performance of the pavement system [1]. However, the bonding condition between adjacent layers was assumed to be full-bond condition or no-bond condition in some of previous research studies [2-8]. It means that the deformation of adjacent layers was completely consistent, and there was no sliding or debonding between adjacent layers in full-bond condition. This is impractical assumption for real pavement structure because slippage and debonding did appear in the asphalt pavement. In a few of research studies mentioned above, the bonding condition between adjacent layers was also assumed to be no-bond condition, but it was an extreme interlayer condition. This is also unreal when the responses of asphalt pavement were calculated in the no-bond condition. In addition, the software BISAR was usually used to calculate the response of semi-rigid base asphalt pavement $[9,10]$, and the model in BISAR established the constraint relation of adjacent layers between horizontal displacement and shear stress. A sliding coefficient $\alpha(0 \leq \alpha<1)$ was used to simulate the bonding condition between adjacent layers, and some possible values of $\alpha$ were used to obtain the range of response of asphalt pavement. However, the real value of $\alpha$ cannot be got to simulate the real bonding condition of asphalt pavement. In fact, some of researchers $[11,12]$ agreed that the bonding 
condition between adjacent layers lies in somewhere between full-bond condition and no-bond condition. A reliable viscoplastic model of natural and synthetic fibres reinforced cold bitumen emulsion mixture is developed and applied to characterize the rutting behavior of asphalt pavement by using finite element analysis [13], but the finite elements are joined to each other by shared nodes. It means that the adjacent layers are full-bond condition. In addition, considering the bonded condition and unbonded condition between two layers, a finite element method with foundation springs and 3-D solid elements was presented to simulate the behaviors of the concrete pavement in the research [14], and a 3-D finite element modeling tool was developed to accurately predict jointed concrete pavement responses due to arbitrary temperature and traffic loads in the research [15] where the contact-friction behaviors between two layers were different from the Coulomb model.

As the bonding condition between adjacent layers plays a significant role on the structural response of asphalt pavements and the asphalt pavement service life, there is a need to develop a novel model to accurately predict the responses of semi-rigid base asphalt pavement. In this study, the interlayer contact bonding model (ICB model) was developed to effectively calculate the responses of semi-rigid base asphalt pavement, which was also a three-dimensional finite element model of asphalt pavement. The study will demonstrate the development of the interlayer contact bonding model and simulating of interlayer contact bonding condition (ICB condition). The responses of semi-rigid base asphalt pavement would be predicted by the ICB model under vehicle load and the detailed calculations for the typical semi-rigid base asphalt pavement considered.

\section{Pavement Structure and Methodology}

2.1. Semi-Rigid Base Asphalt Pavement Structure and Material Property. In this paper, the semi-rigid base asphalt pavement structure is constituted by asphalt concrete upper layer (ACUL), asphalt concrete middle layer (ACML), asphalt concrete lower layer (ACLL), base, subbase, and subgrade, which is shown in Figure 1, and the symmetry of the geometry is along the $z$ axes. To minimize the boundary effect and the effect of mesh size in ANSYS FEM simulation calculation, the final dimensions of the semi-rigid base asphalt pavement structure is $305 \mathrm{~cm}$ wide by $720 \mathrm{~cm}$ long, which was determined by the previous experiences and a lot number of trials. The loading area, meshes of pavement structure, and calculated points are shown in Figures 2(a) and 2(b). The mesh size along $x$ axes and $z$ axes is $5 \mathrm{~cm}$ and $4.5 \mathrm{~cm}$, respectively, near the loading area, and the mesh size of other area along $x$ axes and $z$ axes is $10 \mathrm{~cm}$ and $9 \mathrm{~cm}$, respectively (Figure 2(a)). A vertical, uniform, and single tire load of $0.7 \mathrm{MPa}$ was applied as a vehicle load on the pavement surface having a rectangular loading footprint of $20 \mathrm{~cm}$ in length and $18 \mathrm{~cm}$ in width $[16,17]$, and the shaded areas are the loading area in Figure 2(a). The force of rolling friction between the wheel and the pavement surface satisfies the following relation:

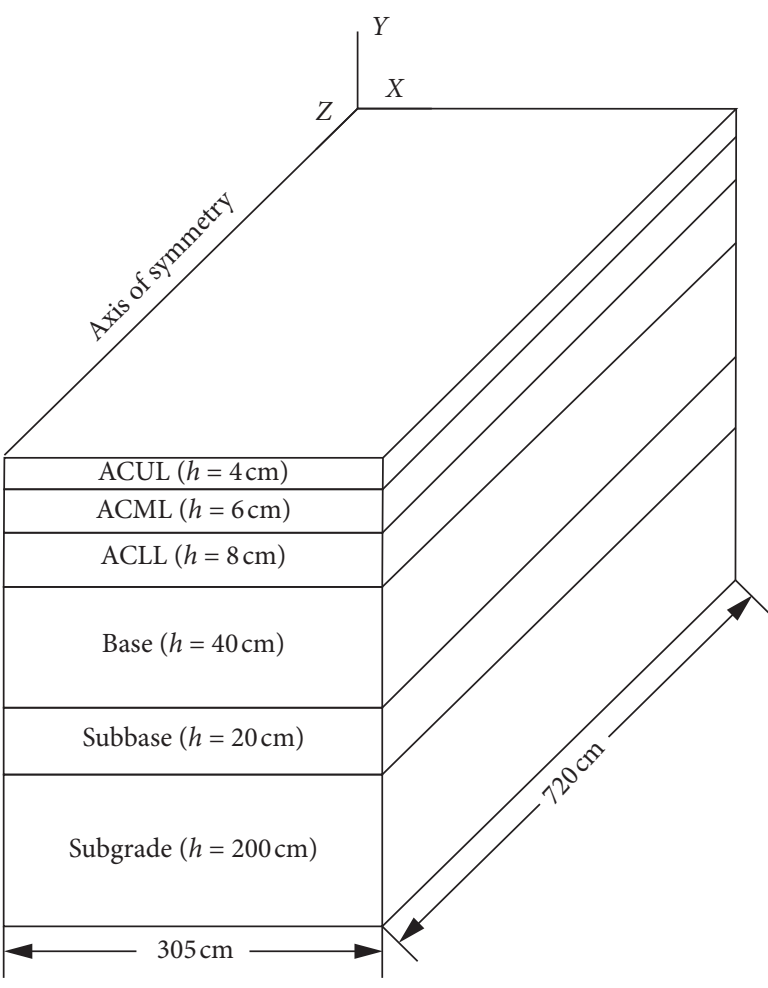

FIGURE 1: Semi-rigid base asphalt pavement structure (not to scale).

$$
f=\mu P,
$$

where $\mu$ is the rolling friction coefficient, which is 0.012 , and $P$ is the pressure. A total number of elements used for ACUL, ACML, ACLL, base, subbase, and subgrade layers were $6192,6192,6192,6192,3096$, and 12384, respectively. Four points shown in Figure 2(b) are used to calculate the response of the pavement structure at different locations; the displacement along $Y$ direction of $A$ at the top of ACUL $\left(U_{Y A}\right)$, the strain along $X$ direction and $Z$ direction of $B$ at the bottom of ACLL $\left(\varepsilon_{X B}\right.$ and $\left.\varepsilon_{Z B}\right)$, the strain along $X$ direction and $Z$ direction of $C$ at the bottom of subbase $\left(\varepsilon_{X C}\right.$ and $\left.\varepsilon_{Z C}\right)$, and the strain along $Y$ direction of $D$ at the top of subgrade $\left(\varepsilon_{Y D}\right)$ will be calculated, respectively. These responses are considered as the critical responses $[18,19]$ to analyze the performance of semi-rigid base asphalt pavement structure in this study.

It is well known that asphalt mixture is a viscoelastic material whose stress and strain are affected by temperature and loading time. When asphalt mixture stays at low temperature environment, its deformation is small, where the response of asphalt mixtures can be assumed to be elastic. In fact, the asphalt mixture serves not only at a low temperature environment but also at a relatively higher temperature environment where the influence of temperature is relatively obvious, and asphalt pavement is easy to deform and damage. Therefore, the response of semi-rigid base asphalt pavement will be calculated and analyzed at room temperature and higher temperature environment, respectively, in this paper, and the effect of temperature on asphalt pavement responses can be taken into consideration. 


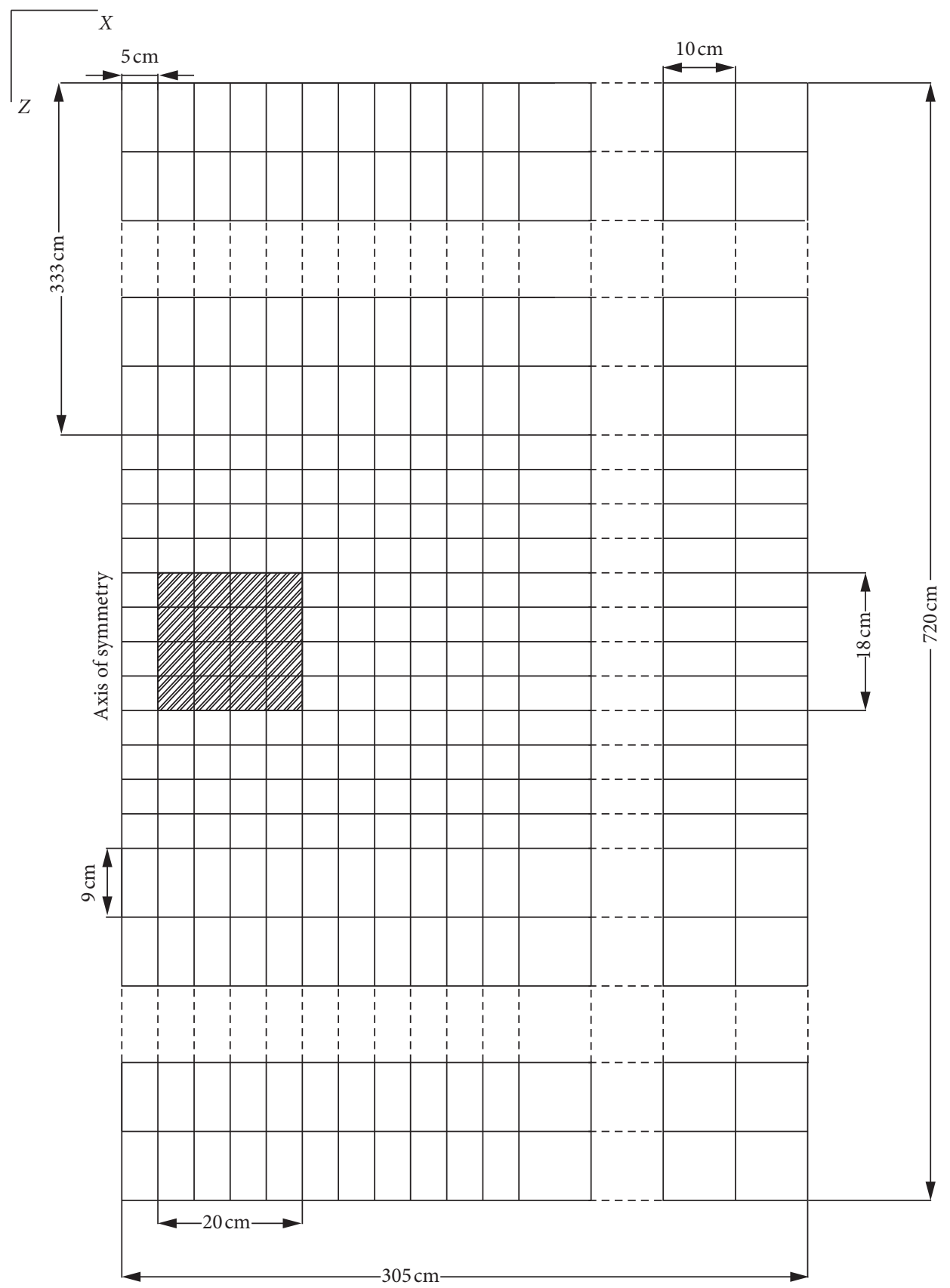

(a)

FIgURE 2: Continued. 


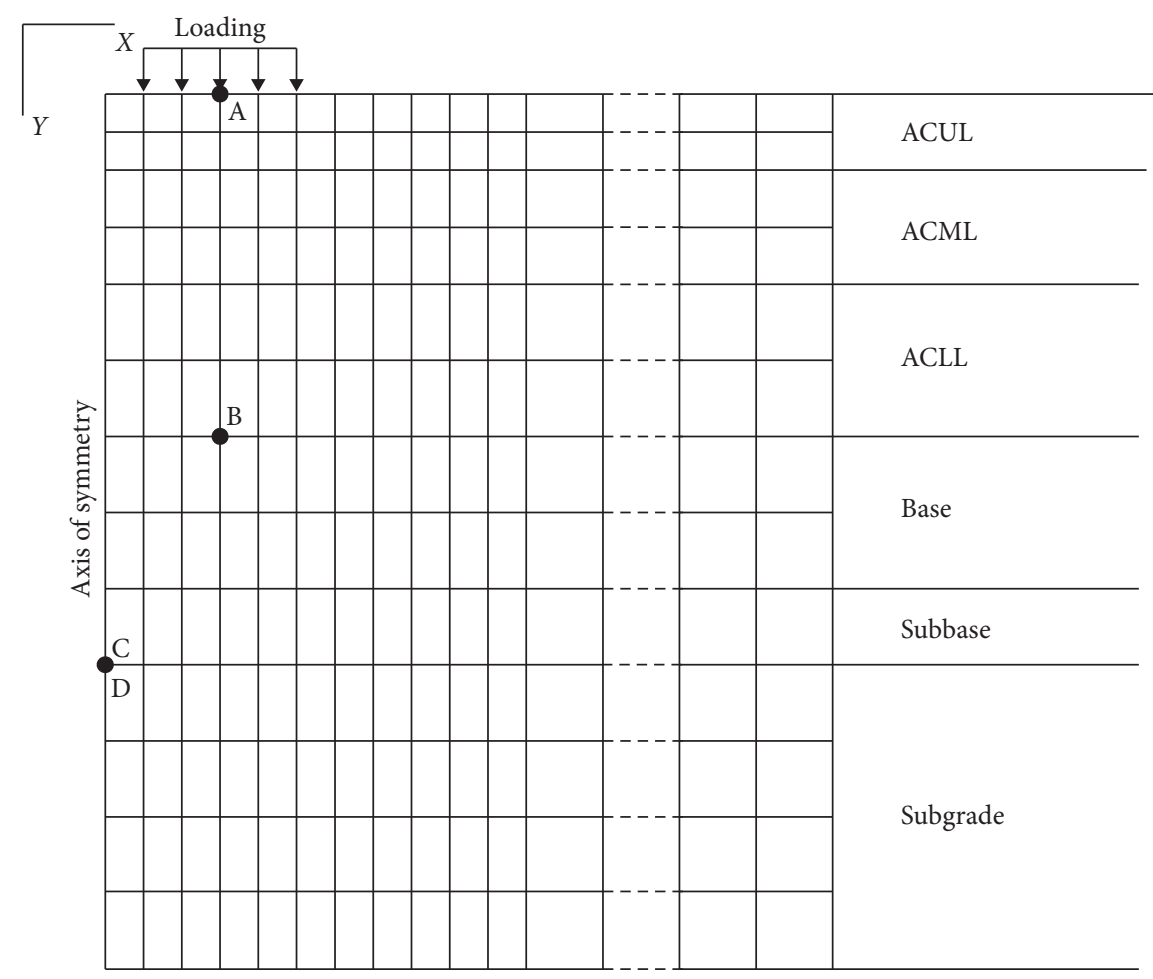

(b)

FIgURE 2: (a) Loading areas and mesh (not to scale). (b) Mesh and calculated points (not to scale).

The material parameters of semi-rigid base asphalt pavement are listed in Table 1 [10], and the temperature of each layer of the asphalt concrete at the high temperature were estimated by the empirical formula LTPP [10], which is as follows:

$$
\begin{aligned}
T= & 54.32+0.78 T_{\text {air }}-0.0025 \operatorname{Lat}^{2}-15.14 \lg (H+25) \\
& +2.055\left(9+0.61 S_{\text {air }}^{2}\right)^{0.5},
\end{aligned}
$$

where $T$ is the temperature $\left({ }^{\circ} \mathrm{C}\right), T_{\text {air }}$ is the mean temperature of the maximum temperature in a week $\left({ }^{\circ} \mathrm{C}\right)$, Lat is the latitude of the observing site $\left(^{\circ}\right), H$ is the depth from the pavement surface $(\mathrm{mm})$, and $S_{\text {air }}$ is the standard deviation of the mean temperature in a week. In this paper, $T_{\text {air }}=36\left({ }^{\circ} \mathrm{C}\right)$, Lat $=34$ (Latitude of Xi'an, China), $S_{\text {air }}=1$, and the temperature profile along the depth of pavement at the higher temperature are shown in Figure 3. Two cases of the room temperature and the higher temperature were taken into account, respectively, and the responses of semi-rigid base asphalt pavement will be computed at these temperature.

\subsection{Interlayer Contact Bonding Model (ICB Model). The} interlayer bonding condition affects stress transmission and energy dissipation of semi-rigid base asphalt pavement structure, meanwhile, which has an important effect on the responses and performance of asphalt pavement. In fact, the bonding condition between adjacent layers is not full-bond condition or no-bond condition but lies in somewhere between full-bond condition and no-bond condition. Therefore, in this study, the interlayer bonding condition was assumed to be contact bonding condition, and the interlayer contact bonding model will be built for more realistic and effective simulating interlayer behavior. For simulating the real interlayer condition, the bonding condition between adjacent layers was assumed to be interlayer contact bonding condition (ICB condition). The concept of the ICB model [20] is illustrated in Figure 4. In the model, the bottom of asphalt concrete upper layer and the top of asphalt concrete lower layer covered with contact element and target element, respectively, and contact element and target element are connected by translational spring element at the corresponding nodes. Similarly, other adjacent layers were all covered with contact element or target element at bottom of upper layer or top of lower layer, respectively.

The interlayer contact bonding condition is different from the full-bond condition and the no-bond condition, and the stress between contactor surface and target surface transfer through translational spring. The translational springs between contactor surface and target surface are used to measure the compression length, and the compression length will be used to calculate response at the corresponding nodes according to contact algorithm [21]. The spring has three degrees of freedom, and three coefficients $K_{n}, K_{t}$, and $K_{s}$ were used to characterize the stiffness along the three different directions. $K_{t}$ and $K_{s}$ represent the tangent stiffness in the interlayer plane (along $x$ direction and $z$ direction, respectively), while $K_{n}$ indicates the normal stiffness perpendicular to the interlayer plane (i.e., $y$ direction). The normal stiffness coefficient and tangent stiffness coefficient are important parameters of the spring, and 
TABLE 1: Material parameters of semi-rigid base asphalt pavement.

\begin{tabular}{|c|c|c|c|c|c|c|c|}
\hline \multirow{2}{*}{ Layer } & \multicolumn{2}{|c|}{ Room temperature } & \multicolumn{2}{|c|}{ Higher temperature } & \multirow{2}{*}{ Poisson's ratio } & \multirow{2}{*}{ Density $\left(\mathrm{kg} / \mathrm{m}^{3}\right)$} & \multirow{2}{*}{ Thickness $(\mathrm{cm})$} \\
\hline & Temperature $\left({ }^{\circ} \mathrm{C}\right)$ & Modulus (MPa) & Temperature $\left({ }^{\circ} \mathrm{C}\right)$ & Modulus (MPa) & & & \\
\hline ACUL & 20 & 1505 & $60(H=20)$ & 310 & 0.30 & 2350 & 4 \\
\hline ACML & 20 & 1220 & $56(H=70)$ & 345 & 0.30 & 2360 & 6 \\
\hline ACLL & 20 & 980 & $52(H=140)$ & 285 & 0.30 & 2370 & 8 \\
\hline Base & - & 1200 & - & 1200 & 0.25 & 2300 & 40 \\
\hline Subbase & - & 300 & - & 300 & 0.35 & 1932 & 20 \\
\hline Subgrade & - & 50 & - & 50 & 0.40 & 1926 & 200 \\
\hline
\end{tabular}

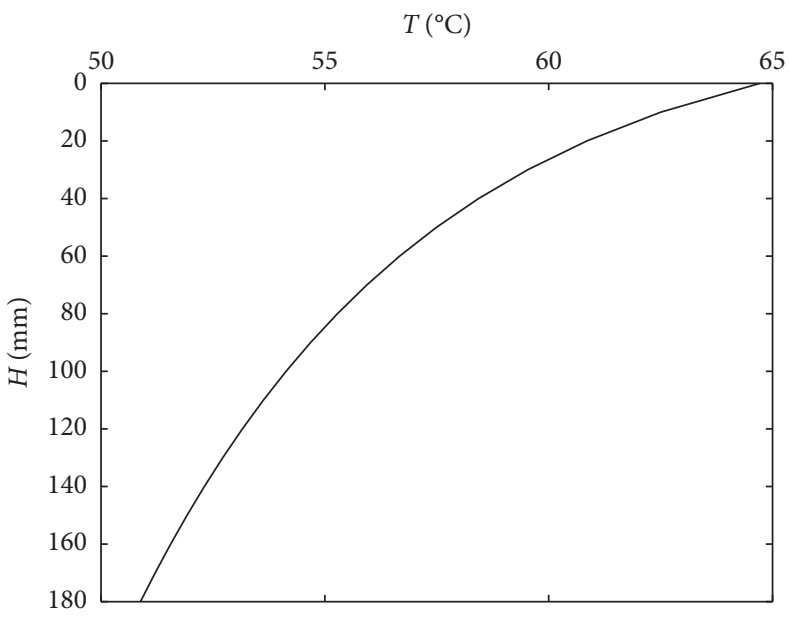

FIgURE 3: Temperature profile along the depth of pavement.

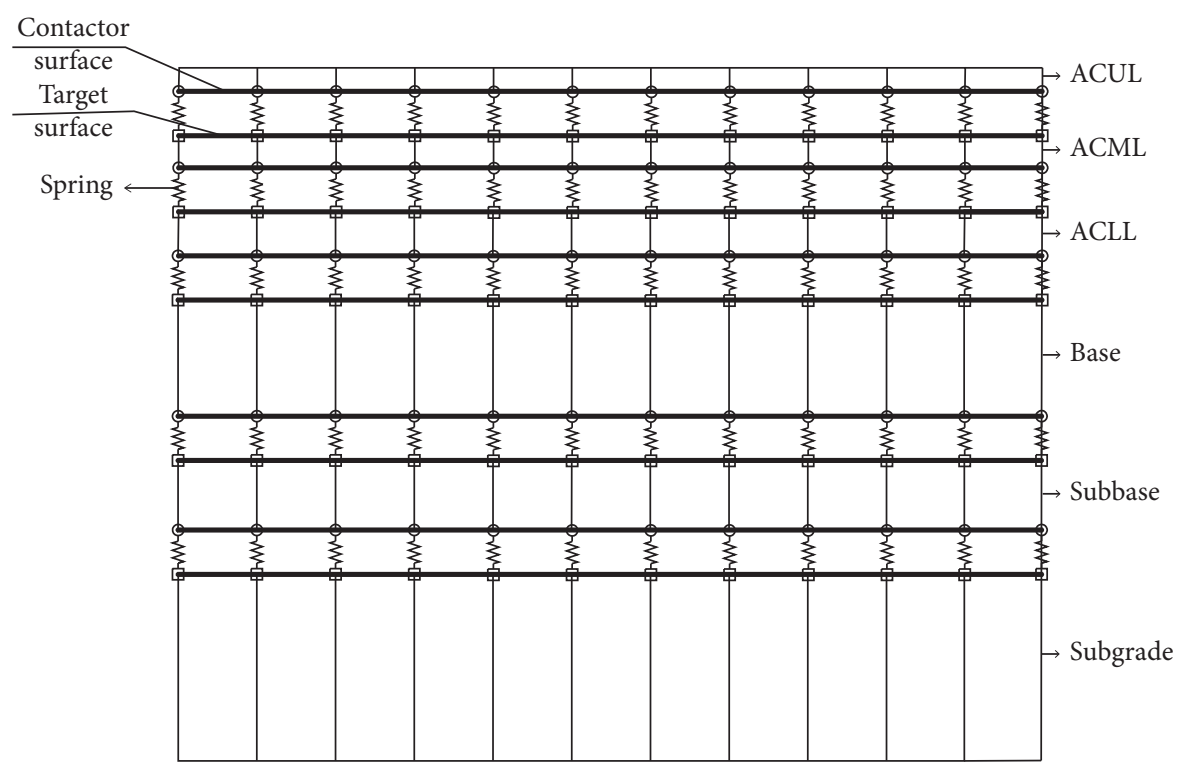

FIGURE 4: Schematic of the interlayer contact bonding model.

they were assumed to be equal and automatically produced by contact algorithm according to material parameters and mesh size in this paper.

In the ICB model, the normal contact stress and tangent contact stress at the corresponding nodes are calculated by the augmented Lagrangian method [21], and the ICB condition between the adjacent layers follows the Coulomb friction model:

$$
\begin{gathered}
\tau_{\lim }=\mu P+b, \\
|\tau| \leq \tau_{\lim },
\end{gathered}
$$


where $\tau_{\lim }$ is the ultimate tangent stress, $\mu$ is the sliding friction coefficient, and $\mu$ equals 0.5 in this paper. $P$ is the contact compressive stress in normal direction, $b$ is the adhesion stress between adjacent layers, and $\tau$ is the equivalent tangent stress. In equation (3), if $\mu$ is 0 or $P$ is 0 , the adhesion stress $b$ between adjacent layers still exist, adjacent layers can keep sticking contact condition. If the adhesion stress $b$ between adjacent layers is 0 , then the two adjacent layers appear as bonding failure. In equation (4), when $|\tau|$ between two adjacent layers is less than or equal to $\tau_{\text {lim }}$, the two layers keep sticking or the two layers start to slide. In this paper, there are five contact bonding layers as shown in Figure 4; the adhesion stress of the first three contact bonding layers are all 0.45 MP [22] and that of the last two contact bonding layers are all $0.01 \mathrm{MP}$.

The asphalt concrete ages with time, and the ageing influences the interface bonding behaviors. As vehicle load chronically and repeatedly acted on the asphalt concrete deck pavement, the disengaging area (bonding failure) might occur sometime between the adjacent layers during the service life of pavements. Previous model may not simulate the insufficient adhesion phenomenon, bonding failure phenomenon, or no-bond phenomenon between the adjacent layers, but the interlayer contact bonding model can simulate these phenomenon by changing the value of the adhesion stress $b$. If the disengaging area occurs between the adjacent layers, the adhesion stress $b$ in equation (1) can be assumed to be 0 in the interlayer contact bonding model. Although the adhesion stress $b$ in the disengaging area is 0 , the adhesion stress $b$ in other area remains unchanged. In this paper, six types of disengaging area are shown in Figure 5 to simulate the bonding failure phenomenon where the dashed box represents the load position on the asphalt concrete surface, and the shaded area under the load position means the disengaging area between the adjacent layers. In order to obtain a uniform mesh, apply vehicle loads, and compare the size of disengaging area and load area, we assume and simplify the shape of the disengaging area to be a rectangle. The disengaging area in type "D0" was none under the loading area, which means that there is no disengaging area between the adjacent layers. The disengaging area in type "D1" is $10 \times 9$, which means that the disengaging area is $10 \mathrm{~cm}$ long by $9 \mathrm{~cm}$ wide between the adjacent layers. The disengaging area in type "D2" was $20 \times 18$, which means that the disengaging area is same with the loading area. The disengaging area in type "D3" was $30 \times 27$, which means that the disengaging area is greater than the loading area. The disengaging area in type "D4" and "D5" were similar to the type "D3," but the size of them was greater than the type "D3."

\section{Response Calculation and Analysis}

The responses at the top and bottom of the semi-rigid base asphalt pavement are the important factors to characterize the performance of asphalt pavement. Hence, it is imperative to accurately predict the response at the top and bottom of pavement structure for more proper evaluation of the pavement's service life. In this paper, the responses at the four points shown in Figure 2(b) would be calculated by the ICB model at the room temperature and the higher temperature, which are used to analyze the performance of semirigid base asphalt pavement under various conditions. The details are as follows.

\subsection{Responses of Pavement Structure under Different Bonding} Conditions. The responses of the semi-rigid base asphalt pavement were calculated with full-bond condition and ICB condition, respectively. The responses of four points shown in Figure 2(b) at the room temperature and higher temperature are listed in Tables 2 and 3, respectively. The negative values denote pressure, and the positive values indicate tension. It is interesting to note the obvious difference in the responses caused due to the different interlayer conditions. The responses with the ICB condition are all increased compared with the responses with the full-bond condition at the room temperature and the higher temperature. The responses at the higher temperature are all increased compared with the responses at the room temperature under different interlayer condition. Compared with the responses of other layers, the change of $\varepsilon_{X B}$ and $\varepsilon_{Z B}$ are more obvious, especially at the higher temperature. $U_{Y A}$ at the higher temperature is increased compared with that at the room temperature, and the bottom of the AC layers is more vulnerable to damage at higher temperatures. Because the performance parameters of base, subbase, and subgrade are invariable at the room temperature or the higher temperature, $\varepsilon_{X C}$ and $\varepsilon_{Z C}$ have the similar increases, and $\varepsilon_{Y D}$ also have the almost same increases. According to the calculation results, using the full-bond condition between the adjacent layers to calculate the responses of the semi-rigid base asphalt pavement structure may underestimate the actual responses of it. The bonding condition between adjacent layers plays a significant role on the serve life of the asphalt pavement. Hence, the ICB condition and model would be used to calculate the responses of the semi-rigid base asphalt pavement structure under different conditions in the rest of the paper.

\subsection{Responses of Pavement Structure with Interlayer Bonding} Failure. To simulate the bonding failure of adjacent layer, the bonding failure is considered between ACLL and base layer, and the disengaging area is assumed to be the six types shown in Figure 5. The responses of the four points were calculated at the room temperature and higher temperature when the different types of disengaging area happened between the ACLL and the base layer, which are listed in Tables 4 and 5, respectively.

$U_{Y A}, \varepsilon_{X C}, \varepsilon_{Z C}$, and $\varepsilon_{Y D}$ under different types of disengaging area make a small change at the room temperature or the higher temperature, which indicates that the bonding failure between the ACLL and the base layer has a small effect on them, and the size of the disengaging area also has almost no influence on them. However, $\varepsilon_{X B}$ and $\varepsilon_{Z B}$ under different types of disengaging area increased significantly at the room temperature or the higher temperature when the size of the disengaging area is bigger and bigger, especially at 


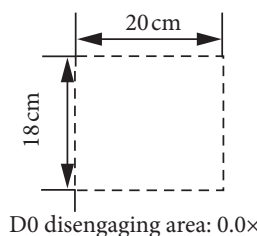

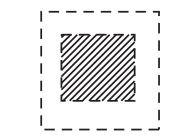

D0 disengaging area: $0.0 \times 0.0$

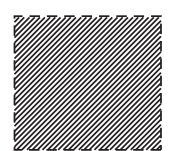

D2 disengaging area: $20 \times 18$

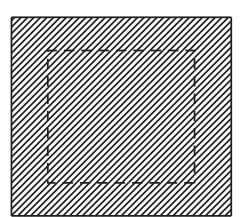

D3 disengaging area: $30 \times 27$

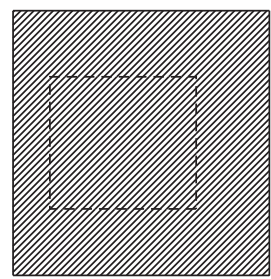

D4 disengaging area: $35 \times 36$

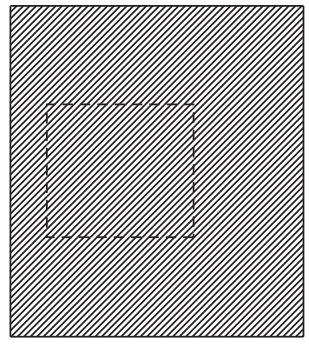

D5 disengaging area: $40 \times 45$

Figure 5: Type of the disengaging area under loading position (not to scale, unit: $\mathrm{cm}^{2}$ ).

TABLE 2: Responses at the room temperature.

\begin{tabular}{|c|c|c|c|c|c|c|}
\hline Interlayer condition & $U_{Y A}(\mathrm{~mm})$ & $\varepsilon_{X B}\left(10^{-6}\right)$ & $\varepsilon_{Z B}\left(10^{-6}\right)$ & $\varepsilon_{X C}\left(10^{-6}\right)$ & $\varepsilon_{Z C}\left(10^{-6}\right)$ & $\varepsilon_{Y D}\left(10^{-6}\right)$ \\
\hline Full-bond condition (1) & -0.267 & 22.828 & 48.087 & 58.976 & 62.794 & -123.971 \\
\hline ICB condition (2) & -0.272 & 30.548 & 56.749 & 62.508 & 66.299 & -143.214 \\
\hline Rate (3) & $1.7 \%$ & $33.8 \%$ & $18.0 \%$ & $6.0 \%$ & $5.6 \%$ & $15.5 \%$ \\
\hline
\end{tabular}

Note: (3) $=\operatorname{abs}((2)-(1)) /(1)) * 100 \%$.

TABLE 3: Responses at the higher temperature.

\begin{tabular}{|c|c|c|c|c|c|c|}
\hline Interlayer condition & $U_{Y A}(\mathrm{~mm})$ & $\varepsilon_{X B}\left(10^{-6}\right)$ & $\varepsilon_{Z B}\left(10^{-6}\right)$ & $\varepsilon_{X C}\left(10^{-6}\right)$ & $\varepsilon_{Z C}\left(10^{-6}\right)$ & $\varepsilon_{Y D}\left(10^{-6}\right)$ \\
\hline Full-bond condition (1) & -0.501 & 39.841 & 58.418 & 73.189 & 78.401 & -155.800 \\
\hline ICB condition (2) & -0.514 & 84.577 & 107.260 & 76.952 & 82.064 & -180.183 \\
\hline Rate (3) & $2.7 \%$ & $112.3 \%$ & $83.6 \%$ & $5.1 \%$ & $4.7 \%$ & $15.7 \%$ \\
\hline
\end{tabular}

Note: (3) $=\operatorname{abs}((2)-(1)) /(1)) * 100 \%$.

TABLE 4: Responses with interlayer bonding failure at the room temperature.

\begin{tabular}{lccccc}
\hline Type of disengaging area & $U_{Y A}(\mathrm{~mm})$ & $\varepsilon_{X B}\left(10^{-6}\right)$ & $\varepsilon_{Z B}\left(10^{-6}\right)$ & $\varepsilon_{X C}\left(10^{-6}\right)$ & $\varepsilon_{Z C}\left(10^{-6}\right)$ \\
\hline D0 & -0.272 & 30.548 & 56.749 & 62.508 & 66.299 \\
D1 & -0.272 & 31.469 & 58.859 & 62.439 & 66.362 \\
D2 & -0.272 & 51.481 & 92.912 & 62.062 & 66.815 \\
D3 & -0.273 & 58.908 & 109.149 & 61.537 & 67.960 \\
D4 & -0.275 & 64.514 & 120.308 & 62.626 & -143.214 \\
D5 & -0.277 & 67.377 & 126.872 & 64.012 & -143.274 \\
\hline
\end{tabular}

TABLE 5: Responses with interlayer bonding failure at the higher temperature.

\begin{tabular}{lccccc}
\hline Type of disengaging area & $U_{Y A}(\mathrm{~mm})$ & $\varepsilon_{X B}\left(10^{-6}\right)$ & $\varepsilon_{Z B}\left(10^{-6}\right)$ & $\varepsilon_{X C}\left(10^{-6}\right)$ & $\varepsilon_{Z C}\left(10^{-6}\right)$ \\
\hline D0 & -0.514 & 84.577 & 107.260 & 76.952 & 82.064 \\
D1 & -0.514 & 88.914 & 116.341 & 76.894 & 82.122 \\
D2 & -0.515 & 167.612 & 244.941 & 76.548 & 82.620 \\
D3 & -0.519 & 199.204 & 309.621 & 75.911 & 84.146 \\
D4 & -0.524 & 220.087 & 353.903 & 77.214 & -180.183 \\
D5 & -0.528 & 230.736 & 379.681 & 78.874 & -180.272 \\
\hline
\end{tabular}


TABLE 6: Responses with different overload level at the higher temperature.

\begin{tabular}{|c|c|c|c|c|c|c|}
\hline Overload level (\%) & $U_{Y A}(\mathrm{~mm})$ & $\varepsilon_{X B}\left(10^{-6}\right)$ & $\varepsilon_{Z B}\left(10^{-6}\right)$ & $\varepsilon_{X C}\left(10^{-6}\right)$ & $\varepsilon_{Z C}\left(10^{-6}\right)$ & $\varepsilon_{Y D}\left(10^{-6}\right)$ \\
\hline 0 & -0.514 & 84.577 & 107.260 & 76.952 & 82.064 & -180.183 \\
\hline 25 & -0.643 & 105.719 & 134.073 & 96.190 & 102.579 & -225.228 \\
\hline 50 & -0.771 & 126.861 & 160.885 & 115.428 & 123.095 & -270.274 \\
\hline 75 & -0.900 & 148.002 & 187.697 & 134.666 & 143.611 & -315.319 \\
\hline 100 & -1.028 & 169.143 & 214.508 & 153.904 & 164.126 & -360.364 \\
\hline
\end{tabular}

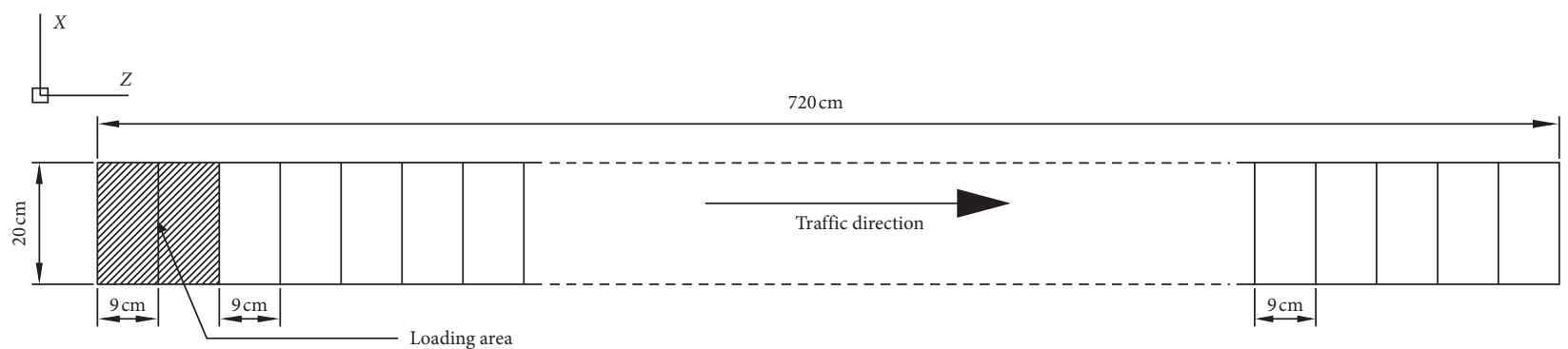

FIgURE 6: Schematic of moving loads.

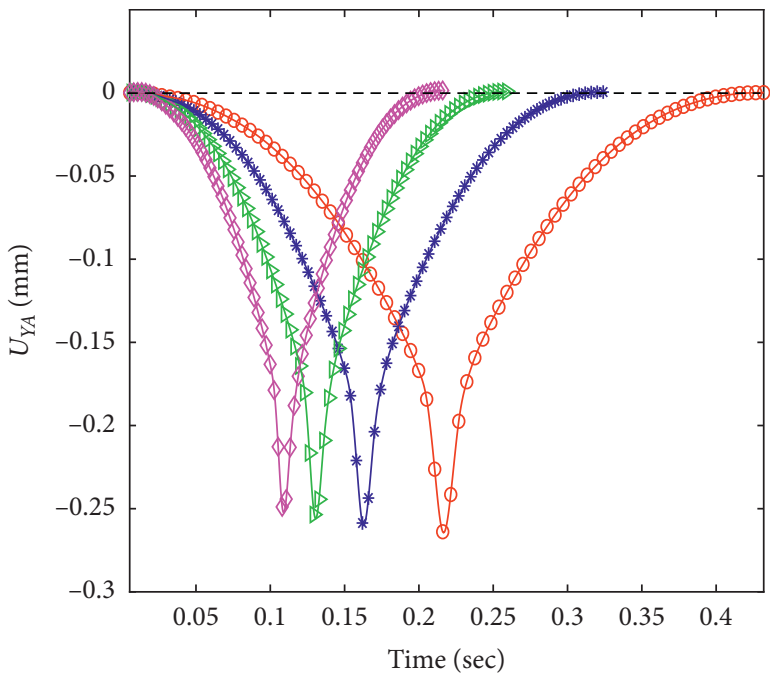

$\begin{array}{ll}\circ V=60 \mathrm{~km} / \mathrm{h} & \triangleright V=100 \mathrm{~km} / \mathrm{h} \\ * V=80 \mathrm{~km} / \mathrm{h} & \diamond V=120 \mathrm{~km} / \mathrm{h}\end{array}$

(a)

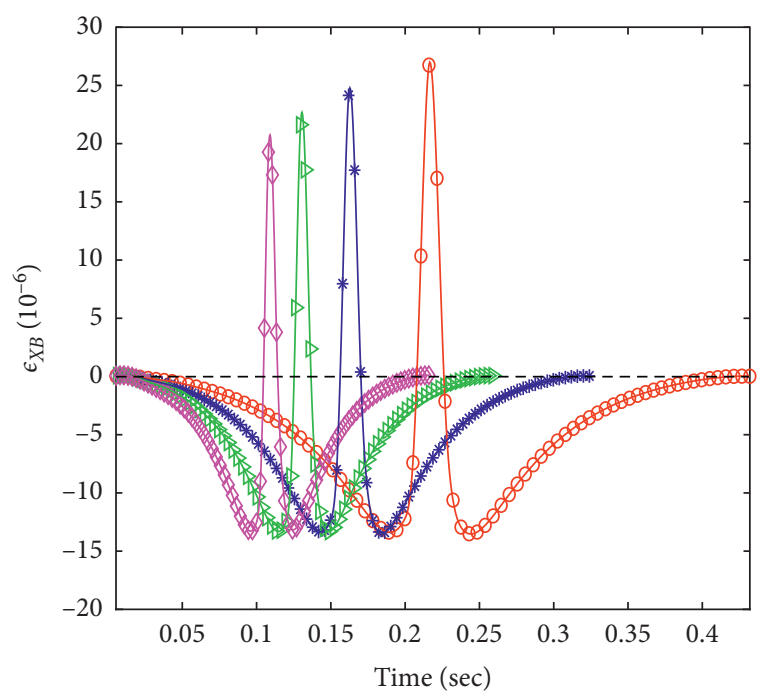
○ $V=60 \mathrm{~km} / \mathrm{h}$
$\triangleright V=100 \mathrm{~km} / \mathrm{h}$
* $V=80 \mathrm{~km} / \mathrm{h}$
$\diamond V=120 \mathrm{~km} / \mathrm{h}$

(b)

Figure 7: Continued. 


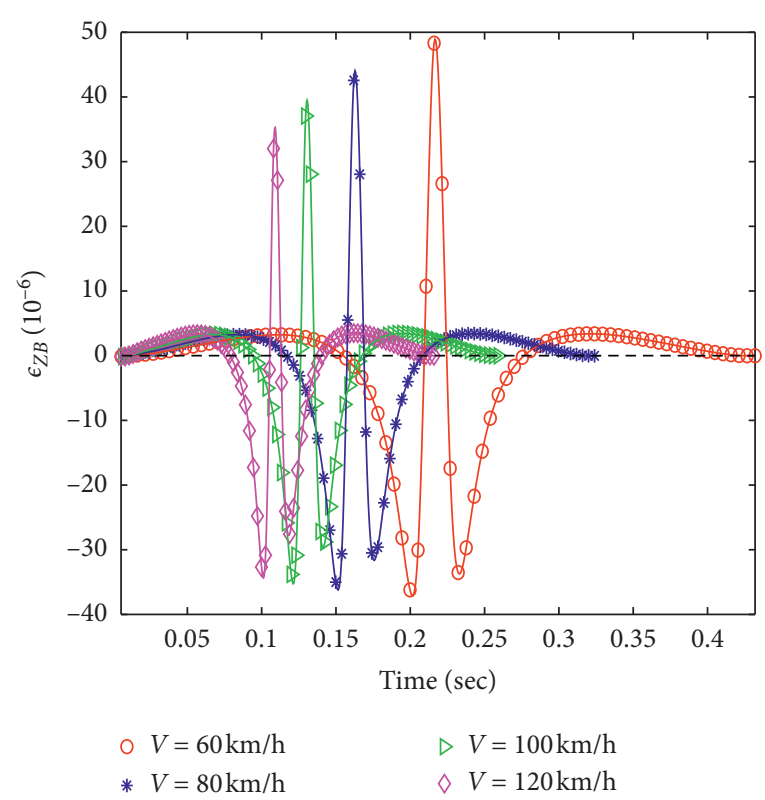

(c)

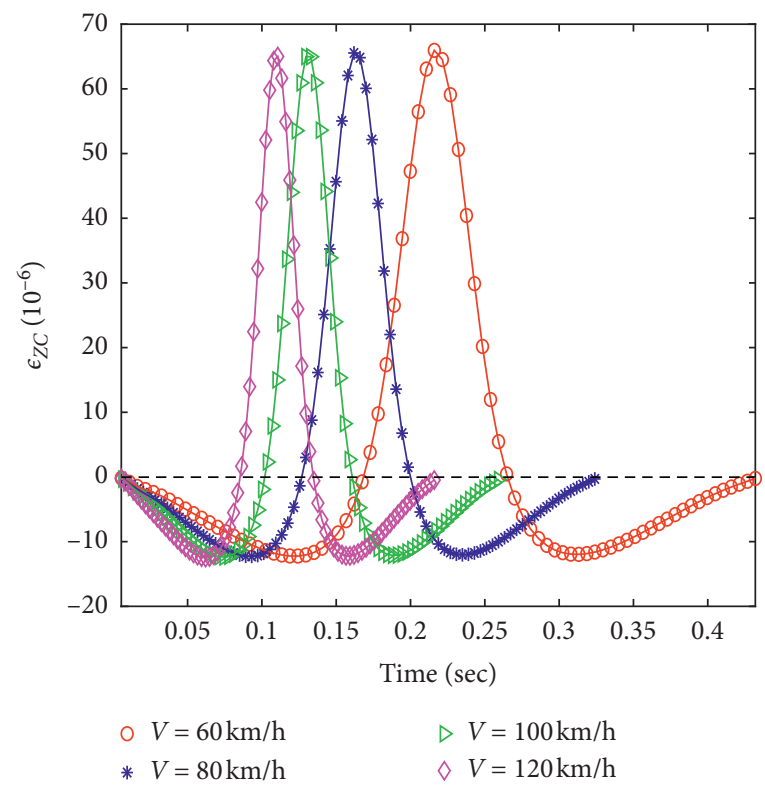

(e)

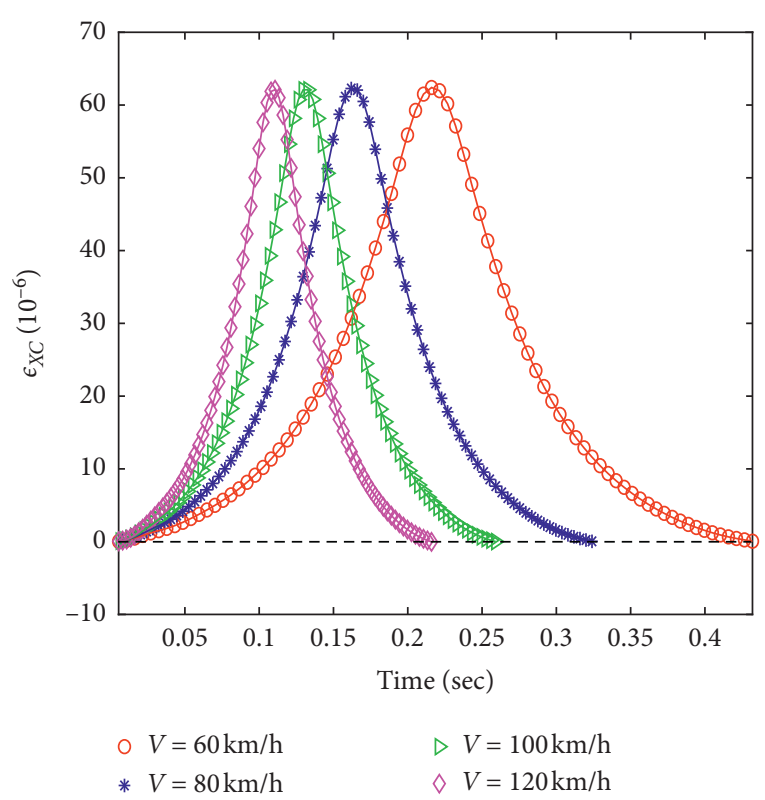

(d)

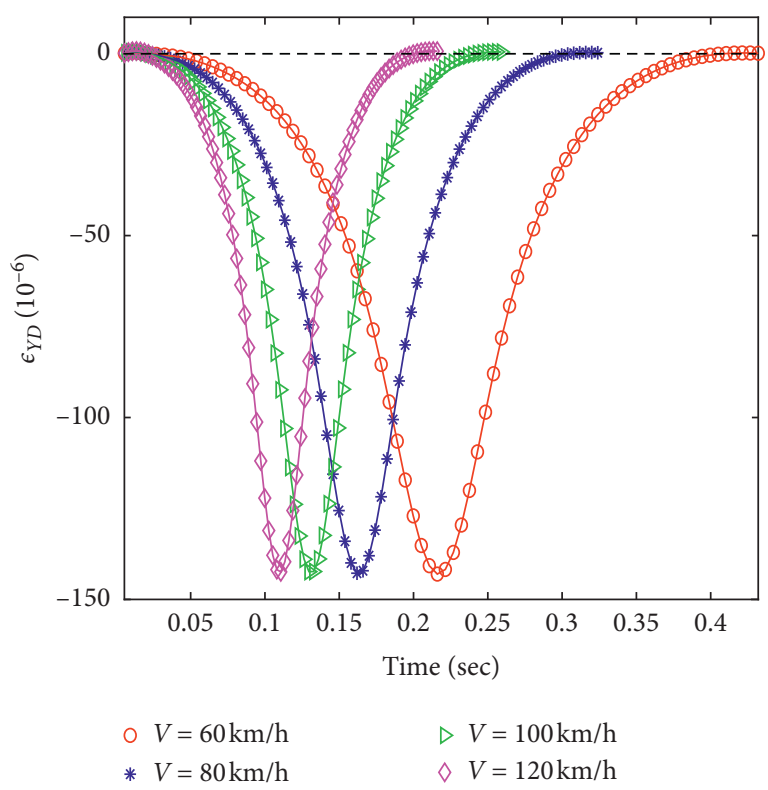

(f)

Figure 7: Response due to moving loads at the room temperature. (a) $U_{Y A}$ at different vehicle speed. (b) $\varepsilon_{X B}$ at different vehicle speed. (c) $\varepsilon_{Z B}$ at different vehicle speed. (d) $\varepsilon_{X C}$ at different vehicle speed. (e) $\varepsilon_{Z C}$ at different vehicle speed. (f) $\varepsilon_{Y D}$ at different vehicle speed.

the higher temperature. It means that the bonding failure between the ACLL and the base layer has an adverse effect on the tensile strain at the bottom of the AC layers, and it is more severe at the higher temperature. The size of disengaging area affects the tensile strain at the bottom of the AC layers, which also changes the stress state near the separation area. Hence, the ACLL and the base layer need a good interlayer bonding condition not only to prevent the emergence of interlayer slippage and disengaging but also to help the adjacent layers form a monolithic structure to resist the influence of traffic loads and environment temperature.
3.3. Responses of Pavement Structure under Overload. The loads applied to the surface of asphalt pavement have a significant effect on the performance of the semi-rigid base asphalt pavement, especially at the higher temperature. So, the responses with different overload level were calculated at the higher temperature, which are listed in Table 6.

With other conditions unchanged, the response of each point at the higher temperature increases with the increase of the overload level. As the loads increase linearly, the responses show a similar linear trend. When the loads doubled, the response of each point is nearly doubled. It 

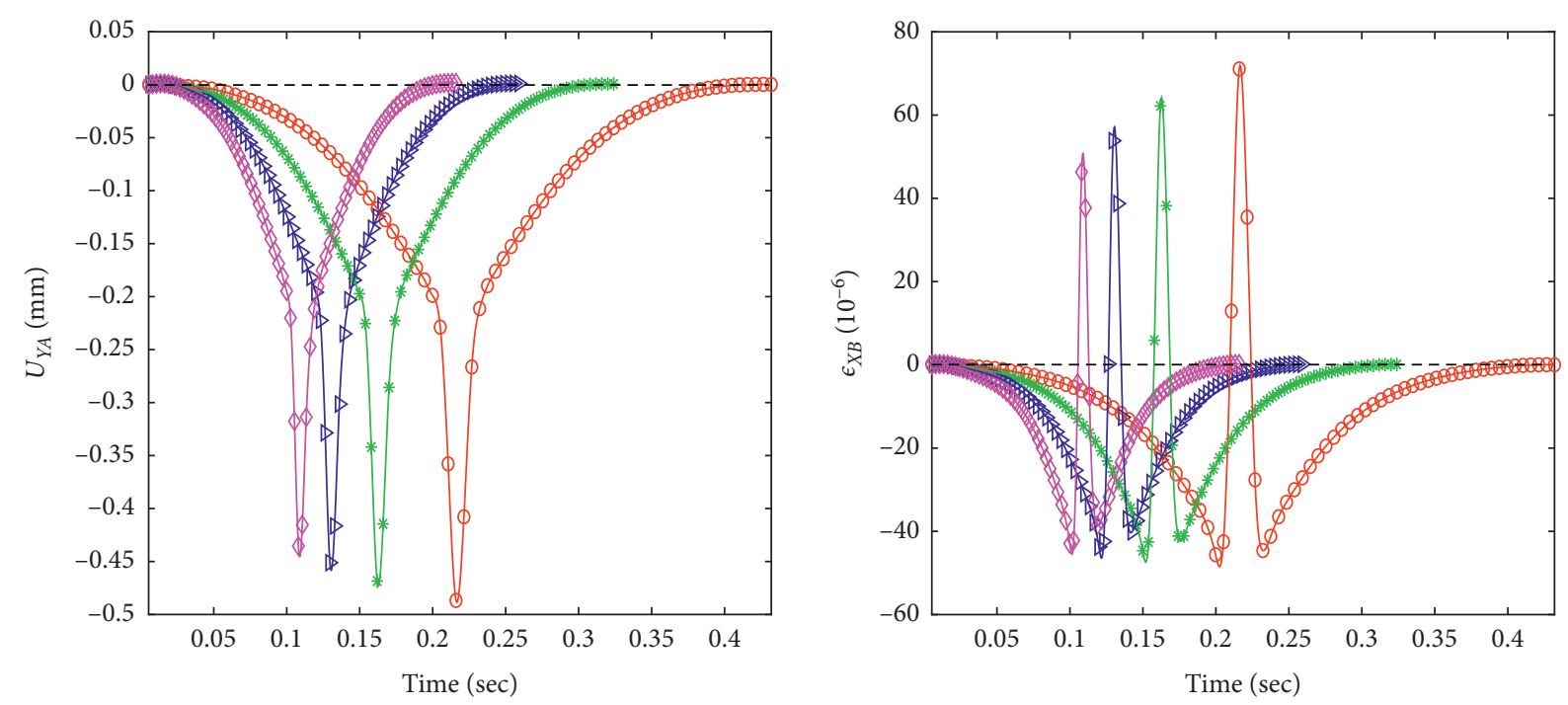
○ $V=60 \mathrm{~km} / \mathrm{h}$
* $V=80 \mathrm{~km} / \mathrm{h}$
$\triangleright V=100 \mathrm{~km} / \mathrm{h}$
$\diamond V=120 \mathrm{~km} / \mathrm{h}$

(a)

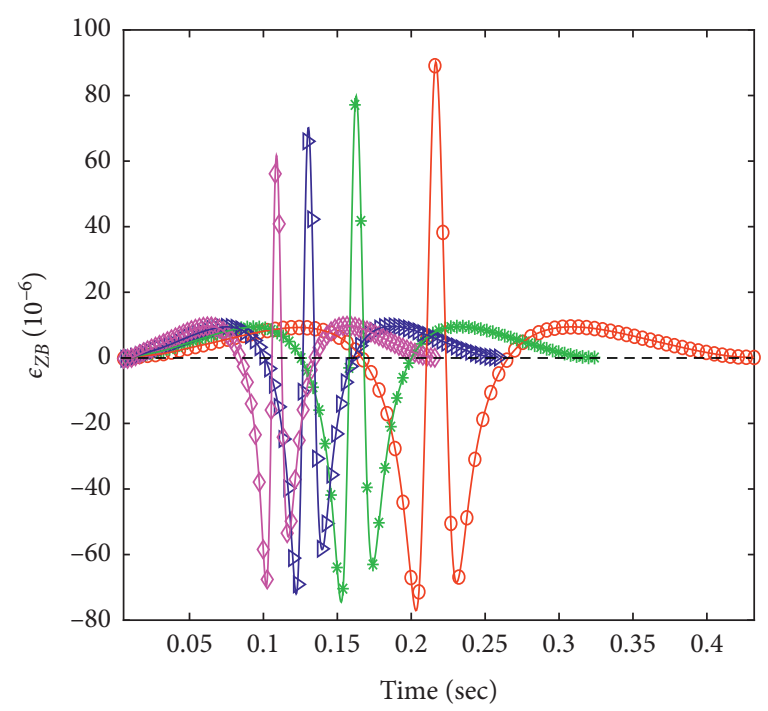
ㅇ $V=60 \mathrm{~km} / \mathrm{h}$
$\triangleright V=100 \mathrm{~km} / \mathrm{h}$
* $V=80 \mathrm{~km} / \mathrm{h}$
$\diamond V=120 \mathrm{~km} / \mathrm{h}$

(b)

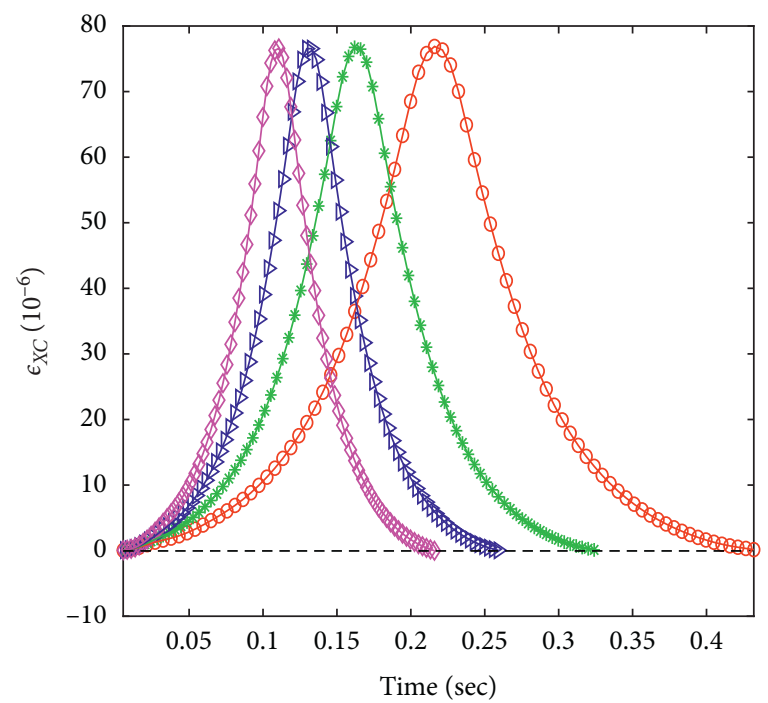
○ $V=60 \mathrm{~km} / \mathrm{h}$
$\triangleright V=100 \mathrm{~km} / \mathrm{h}$
○ $V=60 \mathrm{~km} / \mathrm{h}$
$\triangleright V=100 \mathrm{~km} / \mathrm{h}$
* $V=80 \mathrm{~km} / \mathrm{h}$
$\diamond V=120 \mathrm{~km} / \mathrm{h}$
* $V=80 \mathrm{~km} / \mathrm{h}$
$\diamond V=120 \mathrm{~km} / \mathrm{h}$

(c)

(d)

Figure 8: Continued. 


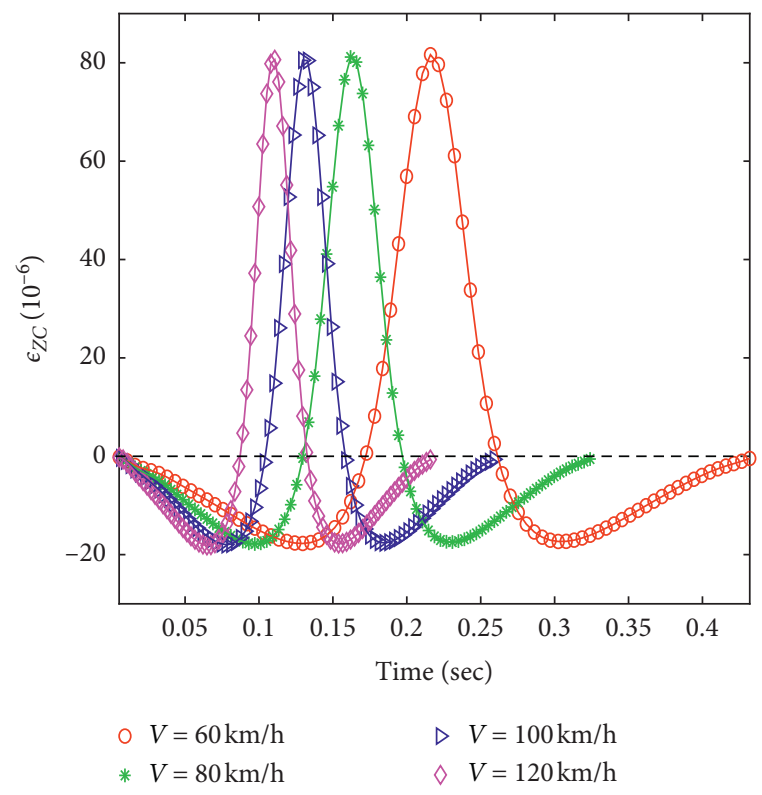

(e)

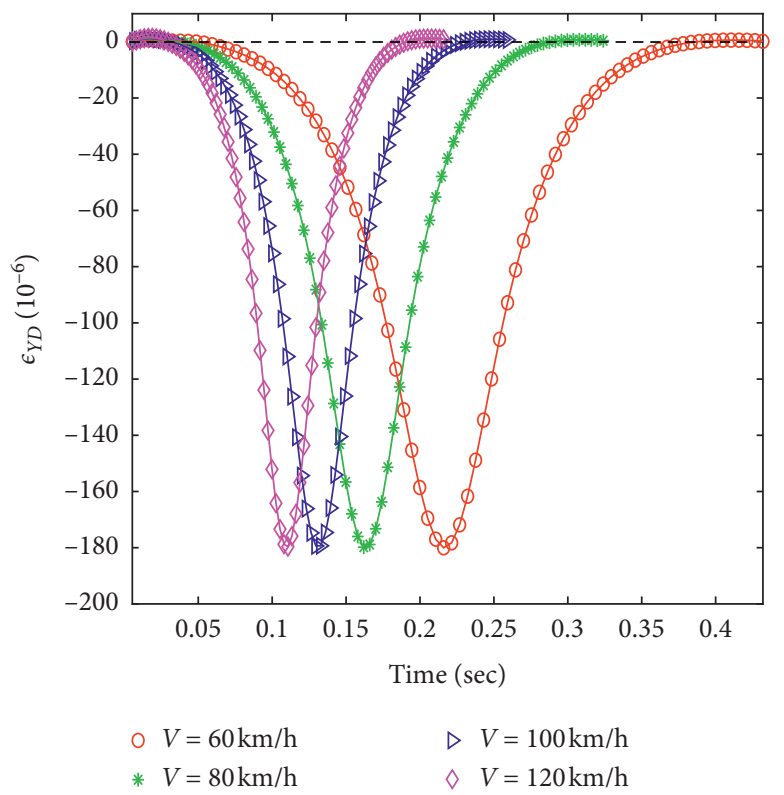

(f)

FIGURE 8: Response due to moving loads at the higher temperature. (a) $U_{Y A}$ at different vehicle speed. (b) $\varepsilon_{X B}$ at different vehicle speed. (c) $\varepsilon_{Z B}$ at different vehicle speed. (d) $\varepsilon_{X C}$ at different vehicle speed. (e) $\varepsilon_{Z C}$ at different vehicle speed. (f) $\varepsilon_{Y D}$ at different vehicle speed.

indicates that semi-rigid base asphalt pavement structure is prone to deformation under the action of overload and higher temperature to cause the base damage and form asphalt pavement diseases.

\subsection{Response of Pavement Structure under Moving Loads.} To know the behaviors of the semi-rigid base asphalt pavement under moving loads, the responses of the four points were also calculated when vehicles pass through the surface of asphalt pavement at the different speed. A schematic of moving loads is shown in Figure 6, where the size of the loading area is $20 \mathrm{~cm}$ by $18 \mathrm{~cm}$, and the length of loading path is $720 \mathrm{~cm}$.

The moving loads step forward $9 \mathrm{~cm}$ along the $z$ axis positive direction in each iteration, and there are totally 80 iterations. The responses of the four points were calculated at the room temperature and the higher temperature when the wheels go through the surface of asphalt pavement at $60 \mathrm{~km} / \mathrm{h}, 80 \mathrm{~km} / \mathrm{h}, 100 \mathrm{~km} / \mathrm{h}$, and $120 \mathrm{~km} / \mathrm{h}$.

Figure 7 shows the responses at the room temperature, and Figure 8 shows the responses at the higher temperature. The responses of AC layer at the higher temperature were obviously greater than that at the room temperature. Although driving at different speeds takes different time, the responses have an approximate trend in the same graph at different speed. In particular, when the vehicle loads are near the calculated points, the responses of AC layer change sharply at the room temperature or the higher temperature. On the contrary, when the vehicle loads are far away from the calculated points, the responses of AC layer change relative gently. This is because the local effect of the vehicle loads is very significant. The maximum of $U_{Y A}$ decreases as the vehicle speed increases at the room temperature and the higher temperature. $\varepsilon_{X B}$ and $\varepsilon_{Z B}$ all have obvious alternating process of compression and tension, and the extreme of them also decreases as the vehicle speed increases at the room temperature and the higher temperature. It may indicate that the shorter the loading time is, the smaller the deformation of asphalt pavement is. $\varepsilon_{X C}$ remains in the tension state, and $\varepsilon_{Z C}$ also have obvious alternating process of compression and tension. $\varepsilon_{X C}, \varepsilon_{Z C}$, and $\varepsilon_{Y D}$ remains nearly unchanged, respectively, in both the quantity and the trend at different speed; furthermore, at the room temperature or the higher temperature, their extremes are almost the same in the same graph. This means that the semirigid base can stably absorb and effectively disperse the vehicle loads. With the vehicle speeds increased, the load period applied on the surface of asphalt concrete pavement is shorter and shorter, and the magnitude and range of deformation caused by vehicle load decreases gradually. So, the responses $U_{Y A}, \varepsilon_{X B}$, and $\varepsilon_{Z B}$ of asphalt concrete layer decreased gradually with the vehicle speeds increased at the room temperature or the higher temperature. In addition to the decreasing load period, the points $C$ and $D$ are further away from the pavement surface than the points $A$ and $B$, and therefore, the responses $\varepsilon_{X C}, \varepsilon_{Z C}$, and $\varepsilon_{Y D}$ only make a small differences at the room temperature or the higher temperature.

\section{Conclusions}

In order to simulate the interface relationship between adjacent layers of semi-rigid base asphalt pavement and accurately capture the responses of asphalt pavement under vehicle loads, the structural response characteristics of the 
typical semi-rigid base asphalt pavement were conducted by the interlayer contact bonding model at the room temperature and the higher temperature, and a summary of conclusions is presented as follows:

(1) The interlayer contact bonding model satisfying Coulomb friction law was developed by means of contact element and target element, which was used to simulate the interface relationship between adjacent layers of semi-rigid base asphalt pavement. The interlayer contact bonding model can not only imitate the partial bond condition between adjacent layers but also model the phenomenon of disengaging between adjacent layers.

(2) The results clearly showed that the responses with the full-bond condition were all less than the responses with the interlayer contact bonding condition at the room temperature or the higher temperature. It may indicate that the responses with the full-bond condition of semi-rigid base asphalt pavement were underestimated, which is a good reason for explaining the early road diseases and damage.

(3) Appearance of interlayer bonding failure makes the strains at the bottom of the AC layer increased when the size of the disengaging area increased between the AC layer and the base layer, especially at the higher temperature. The interlayer bond failure destroys the integrity of the semi-rigid base asphalt pavement structure and reduces the ability of asphalt pavement structure to resist vehicle loads.

(4) The high temperature reduces the stiffness of asphalt pavement, and the overload increases the load on the unit area. The deformation of semi-rigid base asphalt pavement is intensified under the action of the high temperature and the overload. Therefore, the overload should be limited to prolong the life of the asphalt pavement.

(5) The responses of the semi-rigid base asphalt pavement have a similar trend at different speed. The extreme of responses of the AC layer decreases with the increase of the vehicle speed, but the extreme of responses of other layer almost remains unchanged. The adverse effect of moving loads on asphalt pavement is greater than that of road base.

\section{Data Availability}

The data are available from the corresponding author upon request.

\section{Conflicts of Interest}

The authors declare that they have no conflicts of interest.

\section{Acknowledgments}

This research was supported by the National Natural Science Foundation of China (11801441) and the Young Talent Fund of University Association for Science and Technology in Shaanxi, China (20190507).

\section{References}

[1] S. Chun, K. Kim, J. Greene, and B. Choubane, "Evaluation of interlayer bonding condition on structural response characteristics of asphalt pavement using finite element analysis and full-scale field tests," Construction and Building Materials, vol. 96, pp. 307-318, 2015.

[2] M. R. Kruntcheva, A. C. Collop, and N. H. Thom, "Properties of asphalt concrete layer interfaces," American Society of Civil Engineers, vol. 18, no. 3, pp. 467-471, 2006.

[3] H. Ozer, I. L. Al-Qadi, H. Wang, and Z. Leng, "Characterisation of interface bonding between hot-mix asphalt overlay and concrete pavements: modelling andin-situresponse to accelerated loading," International Journal of Pavement Engineering, vol. 13, no. 2, pp. 181-196, 2012.

[4] H. Kim, M. Arraigada, C. Raab et al., "Numerical and experimental analysis for the interlayer behavior of doublelayered asphalt pavement specimens," Journal of Materials in Civil Engineering, vol. 23, no. 1, pp. 12-20, 2012.

[5] Y. Zhang and X. Wang, "Impact of condition on mechanical response of asphalt pavement," Journal of Chang'an University, vol. 32, pp. 7-11, 2012.

[6] S. M. Lazar and E. Diaconu, "Influence of the interface conditions on flexible pavement structures life," Romanian Journal of Transport Infrastructure, vol. 5, no. 1, pp. 30-37, 2016.

[7] D. Cao, Y. Zhao, and G. Fu, "Influence on the surface dynamic viscoelastic deflection of interlayer bonding condition," Journal of Beijing University of Technology, vol. 43, pp. 600605, 2017.

[8] M. Alae, Y. Zhao, S. Zarei et al., "Effects of layer interface conditions on top-down fatigue cracking of asphalt pavements," International Journal of Pavement Engineering, vol. 21, no. 3, pp. 280-288, 2018.

[9] S. Wu, H. Chen, J. Zhang, and Z. Zhang, "Effects of interlayer bonding conditions between semi-rigid base layer and asphalt layer on mechanical responses of asphalt pavement structure," International Journal of Pavement Research and Technology, vol. 10, no. 3, pp. 274-281, 2017.

[10] Y. Luo, Z. Zhang, and K. Zhang, "Sensitivity analysis of influence factors on shear stress of asphalt pavement under high temperature," Engineering Journal of Wuhan University, vol. 51, pp. 895-900, 2018.

[11] J.-P. Zhang, S.-H. Wu, J.-Z. Pel, and Y.-W. Li, "Analysis of mechanical responses of asphalt pavement interlayers based on shear spring compliance," Journal of Highway and Transportation Research and Development (English Edition), vol. 8, no. 1, pp. 1-6, 2014.

[12] F. Wellner and B. Hristov, "Numerically supported experimental determination of the behavior of the interlayer bond in asphalt pavement," Transportation Research Record: Journal of the Transportation Research Board, vol. 2506, no. 1, pp. 116125,2015 .

[13] H. K. Shanbara, F. Ruddock, and W. Atherton, "A viscoplastic model for permanent deformation prediction of reinforced cold mix asphalt," Construction and Building Materials, vol. 186, pp. 287-302, 2018.

[14] N. Aguirre, A. T. Ghalesari, and C. Carrasco, "A comparison of concrete pavement responses using finite element method with foundation springs and 3-D solid elements," in Proceedings of the Airfield and Highway Pavements 2019: Design, 
Construction, Condition Evaluation, and Management of Pavements, pp. 81-90, Chicago, IL, USA, 2019.

[15] A. T. Ghalesari, N. Aguirre, C. J. Carrasco et al., "Evaluation of the response from the rigid pavement analysis system (RPAS) program for the characterisation of jointed concrete pavements," Road Materials and Pavement Design, pp. 1-20, 2020.

[16] X. Hu and L. Sun, "Measuring tire ground pressure distribution of heavy vehicle," Journal of Tongji University (Natural Science), vol. 33, pp. 1443-1448, 2005.

[17] H. Dong, Asphalt Pavement Top-Down Cracks in Laboratory Test, Chang'an University, Shaanxi, China, 2012.

[18] A. Morovatdar, S. R. Ashtiani, C. Licon et al., "Development of a mechanistic approach to quantify pavement damage using axle load spectra from South Texas overload corridors," in Proceedings of the Geo-Structural Aspects of Pavements, Railways, and Airfields Conference (GAP 2019), pp. 60-73, Colorado Springs, CO, USA, 2019.

[19] R. S. Ashtiani, A. Morovatdar, C. Licon et al., "Characterization and quantification of traffic load spectra in texas overweight corridors and energy sector zones," Technical Report No. FHWA/TX-19/0-6965-1, Federal Highway Administration, Washington, DC, USA, 2019.

[20] X. Wang, J. Feng, H. Wang, S. Hong, X. Cheng, and S. Zheng, "Effect of the dynamic load on stresses in a deck pavement with an interlayer contact model," Advances in Civil Engineering, vol. 2018, Article ID 9202958, 10 pages, 2018.

[21] X. Wang, Y. Li, and H. Xu, ANSYS Structural Analysis Unit and Application, China Communications Press, Beijing, China, 2011.

[22] G. White, "State of the art: interface shear resistance of asphalt surface layers," International Journal of Pavement Engineering, vol. 18, no. 10, pp. 887-901, 2016. 